\title{
TECNOLOGIAS EDUCACIONAIS NO ENSINO BÁSICO: EXEMPLOS DE APLICAÇÕES NA ÁREA DE GEOGRAFIA
}

\section{ARTIGO ORIGINAL}

NASCIMENTO, Francisco Ivam Castro do ${ }^{1}$

SILVA, Derlangela Lira da ${ }^{2}$

NASCIMENTO, Francisco Ivam Castro do. SILVA, Derlangela Lira da. Tecnologias Educacionais no Ensino Básico: Exemplos de aplicações na área de Geografia. Revista Científica Multidisciplinar Núcleo do Conhecimento. Ano 05, Ed. 11, Vol. 01, pp. 93-108. Novembro de 2020. ISSN: 2448-0959, Link de acesso: https://www.nucleodoconhecimento.com.br/geografia/area-de-geografia

\section{RESUMO}

A rapidez com que as mudanças tecnológicas ocorrem tem modificado de forma direta o modo como os alunos e professores obtém novos conhecimentos. Entre estas tecnologias cabe destacar a importância que os aplicativos estão exercendo no processo de ensino e aprendizagem nos dias atuais. Diante disso, este trabalho teve como objetivo elaborar uma análise qualitativa sobre os aplicativos Onde é isso?, Geografia mundial e LandscapAR, destacando as limitações e potencialidades destas ferramentas enquanto tecnologias educacionais, além de analisar questões teóricas sobre a influência das tecnologias da informação e comunicação (TIC) para o ensino de geografia. Este estudo foi desenvolvido a partir do método de análise bibliográfica e análise de conteúdo, permitindo a compreensão e interpretação dos fatos para o descobrimento de novos conhecimentos. As análises apontam para a importância do

1 Mestre em Desenvolvimento Regional. Especialista em Geoprocessamento e Análise Ambiental. Bacharel em Geografia.

2 Especialista em Tecnologia da Informação e Comunicação. Licenciada em Geografia. 
uso de tecnologias voltadas para o campo educacional como forma de melhorar o processo de ensino e aprendizado. Estas tecnologias envolvem o uso de informações por meios eletrônicos, utilização de equipamentos de multimídia, comunicação distributiva e simulação da realidade por meio de realidade aumentada e plataformas de ensino. Os aplicativos Onde é isso?, Geografia mundial e LandscapAR se mostraram como potenciais ferramentas para serem utilizadas no ensino de geografia, principalmente para os alunos que estão começando a ter os primeiros contatos com as formas territoriais dos diferentes países. Estes aplicativos são acessíveis e fáceis de usar. Porém, alunos de baixa renda podem não ter acesso a estas ferramentas devido aos custos de aquisição de equipamentos eletrônicos no Brasil. Com isso, as tecnologias e aplicativos analisados ao longo do artigo podem ser úteis para o ensino de conteúdos geográficos, mas não podem ser utilizados como única ferramenta de ensino, cabendo ao professor o papel de aprofundar os conhecimentos que os alunos conseguem obter por meio dos aplicativos.

Palavras-chave: Geografia, Tecnologia da Informação e Comunicação, aplicativos.

\section{INTRODUÇÃO}

Uma das principais características da sociedade atual é a velocidade e facilidade com que as comunicações são feitas. Estas transformações são frutos da popularização das Tecnologias da Informação e Comunicação (TIC) que também contribuem para modificar a forma como nos comportamos e interagimos no espaço geográfico.

Tratam-se de transformações que envolvem variados setores da sociedade, ocorrendo com uma imensa rapidez, o que implica em mudanças rápidas e profundas, em especial no campo educacional. Para Izoton (2020) percebe-se que a tecnologia da informação se constitui em parte inerente à vida dos seres humanos atualmente, não sendo mais possível desconsiderá-la em nenhum âmbito, inclusive na questão educacional.

A rapidez com que as mudanças tecnológicas ocorrem modificam de forma direta o modo como os alunos, professores e técnicos educacionais lidam com a 
aprendizagem. Pensar sobre a abrangência e as possibilidades de uso das novas tecnologias, que envolvem desde as opções de hardware, softwares e técnicas de aprendizagem, se constitui uma tarefa difícil e complexa, porém de extrema necessidade, principalmente para os professores de geografia que estão em busca de novas ferramentas digitais e metodologias de ensino.

A necessidade de pesquisas que procuram entender como as tecnologias educacionais, em espacial as ligadas ao ensino de geografia, contribuem para o processo de ensino e aprendizagem se dá mediante as crescentes indagações sobre a importância de inserir estas tecnologias no contexto educacional. Esta necessidade é vista no crescente número de trabalhos e pesquisas que tratam da relação existente entre a tecnologia e suas diferentes formas de uso nas práticas de ensino. Isto demonstra a necessidade de pesquisas que contribuam para que o ambiente educacional se prepare para que as mudanças tecnológicas que estão ocorrendo no seio da sociedade possam ser absorvidas e utilizadas da melhor forma na busca de um ensino eficaz.

Neste sentido, este trabalho tem como objetivo elaborar uma análise qualitativa sobre os aplicativos Onde é isso?, Geografia mundial e LandscapAR, destacando as limitações e potencialidades destas ferramentas, enquanto tecnologias educacionais para o ensino de geografia no ensino básico. Além da opinião de autores sobre as potencialidades das tecnologias no âmbito educacional, serão destacadas as principais contribuições destas ferramentas para auxiliar no ensino da disciplina de geografia nas escolas.

\section{MÉTODOS}

Este estudo foi desenvolvimento a partir do método de análise bibliográfica e da análise de conteúdo, que de acordo com Oliveira et al. (2003) é uma técnica de pesquisa popular na área das Ciências Humanas, onde possui como característica a interpretação dos fatos para descobrir novos conhecimentos. Estes métodos de análise também buscam apresentar novas ideias e conceitos a partir de trabalhos já publicados e validades pela comunidade científica. 
A seleção das referências utilizadas ocorreu por meio de consultas em sites de revistas científicas e portais educacionais. Os aplicativos selecionados para serem analisados quanto a sua funcionalidade para o ensino de geografia levaram em consideração a quantidade de downloads, funcionalidades e disponibilidade de versão em língua portuguesa.

\section{DESENVOLVIMENTO}

De acordo com Gebran (2009) a internet foi inserida no Brasil por volta de 1988, graças aos esforços da grandes instituições: Fundação de Amparo à Pesquisa de São Paulo (Fapesp), Laboratório Nacional de Computação Científica (LNCC) e Universidade Federal do Rio de Janeiro (UFRJ)[3].

O desenvolvimento da internet e das tecnologias associadas, principalmente a partir de 1988, propiciaram mudanças substanciais em vários setores da sociedade, em especial para o setor educacional. O modelo de acumulação e produção do capital também sofreram grandes mudanças, onde a informação passou a ser a principal commodity.

De acordo com Júnior, Mello e Gobara (2020) vivemos um momento ímpar na história das revoluções tecnológicas, pois está acorrendo um progressivo e veloz desenvolvimento de instrumentos tecnológicos que influenciam e transformam as relações sociais de forma continua. A criação de novos produtos e aplicações são fruto da criatividade e das inovações que possuem como fonte principal o desenvolvimento tecnológico. Para Souza e Pinho (2016) a criatividade precede a concepção de inovar, pois falar em inovação pressupõem o surgimento de uma ideia criativa que será organizada e materializada em um novo produto.

$\mathrm{Na}$ educação, o processo de criação poderá fazer surgir novos modelos de ensino e práticas pedagógicas. Percebe-se que a inovação na educação requer que além do uso de ferramentas tecnológicas, sejam criadas novas formas de educar, onde o principal objetivo deverá ser o de contribuir com o crescimento intelectual dos alunos[4]. 
A inovação no ambiente educacional é caracterizada pela criação de novas tecnologias e metodologias educacionais que contribuam para que os alunos possam aprender com mais eficácia. É importante destacar que a inovação deve partir de todos os atores que fazem parte do sistema educacional.

Com isso, as análises sobre as tecnologias educacionais no âmbito do ensino médio para a área de geografia se baseia sobretudo nas tecnologias que mais influenciam no processo de ensino/aprendizado e as inovações realizadas que de alguma forma contribuíram ou ainda contribuem para o ensino do conhecimento geográfico. Porém, sobre as tecnologias, Baptista (2020) faz uma crítica afirmando que

[...] com o avanço da tecnologia, a escola é chamada a desenvolver competências e habilidades necessárias à reprodução do capital, havendo apenas lugar para aqueles que desenvolvem as qualidades técnicas necessárias ao mercado. Neste sentido, as tecnologias ocupam um importante papel no processo de ensino/aprendizado uma vez que auxilia a escola e os profissionais que dela fazem parte, desenvolver estratégias adequadas para o ensino (BAPTISTA, 2020 p.291).

Mesmo sendo importante para o processo educacional, Baptista (2020) destaca que o uso das tecnologias disponíveis atualmente está servindo para formar pessoas para servirem aos interesses do capital, estando o sujeito à mercê das constantes mudanças que ocorrem no mercado. Neste sentido, a escola além de oferecer, por meio das tecnologias, uma educação capaz de formar alunos com ótimas capacidades técnicas, deverá também formar alunos críticos e cientes dos problemas sociais existentes. De acordo com Cunha

A partir dessa base teórica, assumimos, enquanto um coletivo de estudos e pesquisas, a perspectiva da inovação como ruptura paradigmática. Compreendemos não se tratar apenas de acionar mudanças metodológicas ou prover a inclusão de recursos tecnológicos, referimo-nos, principalmente, a uma nova forma de compreender o conhecimento e, portanto, a uma alteração nas bases epistemológicas da prática pedagógica (CUNHA, 2016 p.94).

Durante anos o ambiente escolar, que acompanhou a evolução da humanidade, se manteve praticamente inalterado diante do surgimento de novas tecnológicas. As 
inovações que iam surgindo eram utilizadas somente como suporte ao processo de leitura e de escrita. Porém, é possível observar que nas últimas décadas as TICs têm ganhado cada vez mais espaço no contexto escolar.

Segundo Fino (2011) a inovação pedagógica só se pode colocar em termos de mudança e de transformação, que neste caso deverá estar empenhada em garantir a qualidade da aprendizagem com o mínimo de tempo possível. Quando alcançado este modelo permitirá a redução de custos financeiros e de tempo para que um determinado conteúdo seja ensinado. Ainda é possível afirmar que

Dentre algumas medidas tomadas ao longo do mundo na relação entre TIC, equidade e educação, podemos citar a China, que forneceu computadores, pacotes de dados móveis e subsídios de telecomunicações para estudantes de famílias de baixa renda. A França, por sua vez, emprestou dispositivos e forneceu tarefas impressas para $5 \%$ dos alunos que não possuem acesso a internet ou acesso a computadores no país (SOUSA; BORGES; COLPAS, 2020 p.154).

As inovações e criações tecnológicas, tendo como exemplos os dispositivos móveis, atualmente são consideradas ferramentas primordiais para o processo de ensinoaprendizagem. Estas ferramentas vieram para complementar o processo de ensino. Destaca-se que a incorporação da tecnologia, bem como a disponibilização dela para os alunos de baixa renda é uma necessidade que deve ser implementada em escolas situadas nas regiões mais pobres deste país.

O uso dos recursos digitais disponíveis, quando feito de forma eficiência e com planejamento adequado, é capaz de tornar o ambiente escolar mais atrativo, uma vez que um amplo conjunto de tecnologias já fazem parte do cotidiano dos alunos. De acordo com Guerra

A evolução da tecnologia é um tema em alta na atualidade. O mundo está cada vez mais conectado e a cada dia as mídias digitais se tornam mais acessíveis. Não se pode negar que as inovações tecnológicas atingiram vários segmentos da sociedade moderna e na educação não foi diferente. Cada vez mais as novas tecnologias invadem a sala de aula, tornando-se importantes ferramentas didáticas, proporcionando um aprendizado diferenciado a partir da inovação nos métodos pedagógicos (GUERRA, 2020 p.40). 
Neste sentido, o uso das tecnologias da informações e comunicação na escola permite que esta possa vivenciar uma nova realidade, onde tanto os alunos quanto os educadores possam se beneficiar.

\subsection{TECNOLOGIAS APLICADAS AO ENSINO DE GEOGRAFIA}

De acordo com Kenski (2012), Pinto (2005), Brito e Puriticação (2008), Garcia e Camas (2020) a tecnologia pode ser considerada o resultado de um processo de evolução humana, tendo como objetivo melhorar a sua qualidade de vida por meio do desenvolvimento de técnicas ferramentas.

Pensar a educação para além do espaço de ensino tradicional é considerado um esforço que pode gerar inovação. $O$ ensino precisa ser pensado no sentido de romper barreiras, incorporando novos elementos, significados e metodologias capazes de fazer com que os alunos despertem o gosto pelo aprendizado de conhecimentos geográficos.

Atualmente, todas as disciplinas que fazem parte do currículo escolar do ensino médio podem fazer uso das tecnologias disponíveis. Ao fazer uso destas tecnologias, o docente está rompendo com a forma tradicional de ensinar um determinado conteúdo. É importante destacar que as inovações e tecnologias que envolvem o ensino de forma remota, requerem uma maior atenção, tanto do professor quanto do aluno. Neste tipo de ensino a interatividade deve garantir que os alunos possam tirar todas as dúvidas. Os professores que conseguem manter um alto nível de produtividade e interatividade no ambiente virtual podem obter resultados de aprendizagem semelhantes aos vistos nas aulas presenciais. Porém, é necessário destacar que a sala de aula ainda é o espaço por excelência da aprendizagem.

Para Moran (2015) os recursos digitais disponíveis podem contribuir para que os professores combinem atividades integradas dentre e fora da sala de aula. A proposta seria repassar informações e atividades de forma virtual e aproveitar os encontros em sala de aula para discutir, apresentar os resultados e se aprofundar nas discussões. 
Neste sentido, as TICs são ferramentas que permitem aumentar as possibilidades de inovar. Para isso, se faz necessário a adoção de práticas pedagógicas que estejam de acordo com a realidade dos alunos e do ambiente escolar na qual este aluno está inserido. As TICs não devem ser encaradas como um substituto do papel do professor, mais sim como uma possibilidade de incorporação das tecnologias para o desenvolvimento de aulas mais atrativas e inovadoras no ambiente escolar. No quadro 1 é possível visualizar algumas tecnologias existentes que podem ser uteis para 0 processo de ensino e aprendizagem da geografia.

Quadro 1. Inovações tecnológicas que podem ser utilizadas para o ensino de geografia.

Definição

1. Apresentação de informações

\section{Inovações tecnológicas e pedagógicas na educação}

Utilização de ambientes virtuais como forma de aperfeiçoar técnicas de ensino e exposição de conteúdo. É por meio de ambientes virtuais que alunos e professores podem ampliar suas pesquisas, expor conteúdos, resultados, entre outros. São exemplos de ambientes virtuais de aprendizagem gratuitos o Google Meet e o Moodle.

2. Obtenção de Nos dias atuais os alunos dispõem de ferramentas capazes que informações podem ser uteis para a obtenção de informações, além daquelas passadas pelos professores. Os dados e informações podem ser obtidos por meio de sites, plataformas virtuais, bibliotecas digitais, revistas científicas, canais no Youtube, entre outros.

3. Comunicação Este tipo de comunicação tem revolucionado a forma como os distributiva professores e alunos se interagem fora da sala de aula. Com o avanço da qualidade da internet torna-se possível utilizar ferramentas de teleconferência, tais como: google meet, zoom, entre outros, para a comunicação entre o professor e seus alunos. 


\section{Multimídia \\ Textos, fotos e vídeos podem ser utilizados de uma forma inovadora para ajudar na compreensão de conteúdos complexos. As inovações por meio da utilização de multimídias possuem como vantagem a possibilidade de acesso a qualquer hora, dia ou plataformas que suportam os diferentes formatos de arquivos multimídias. Outra vantagem é a possibilidade do aluno poder assistir o vídeo várias vezes. \\ 5. Simulação Com a simulação o aluno pode conhecer vários locais que antes eram inacessíveis devido aos custos financeiros e dificuldades logísticas. A simulação de ambientes e de objetos por meio de modelos digitais podem ajudar o aluno a compreender melhor sobre um determinado assunto. \\ 6. Realidade Por meio desta tecnologia os alunos podem interagir com virtual objetos e paisagens simuladas tridimensionalmente. A realidade virtual, quando utilizada da forma correta pode representar uma verdadeira revolução para o ensino de geografia, principalmente relacionados ao conteúdo da geografia física, tais como: relevo, rios, vegetação, entre outros. Por se tratar de uma tecnologia ainda recente, não é comum observar professores utilizando a realidade virtual como metodologia de ensino. \\ 7. Realidade A realidade aumentada também é considerada uma tecnologia aumentada que aos poucos está sendo inserida no contexto educacional. É caracterizada por incluir componentes que podem interagir com o que já existe. Neste caso, um professor que esteja ensinando sobre um determinado relevo pode projetá-lo tridimensionalmente sobre uma superfície onde os alunos poderão visualizar todos os detalhes da projeção.}

Adaptado de GIORDAN; JACOBSOHN; FILATRO (2005). 
Inovações na área de realidade aumentada ainda são pouco exploradas no campo educacional brasileiro, principalmente em escolas públicas, pois os equipamentos que auxiliam nestas áreas ainda são considerados de alto custo. Outro impedimento para a adoção das tecnologias apontadas no quadro 1 é a pouca quantidade de computadores por aluno nas escolas públicas. A utilização de computadores contribui para que os alunos aprendam novas técnicas computacionais que vão além da aplicação da realidade aumentada.

Os avanços tecnológicos têm permitido representar os elementos do mundo real em ambientes virtuais por meio dos dispositivos eletrônicos. Existem aplicativos que podem tornar a câmera de um celular, por exemplo, capaz de projetar a visualização em 3D de um determinado objeto. O aplicativo LandscapAR (figura 1) é um exemplo de tecnologia que pode ser utilizada para o ensino de conteúdos geográficos no ensino básico.

Figura 1 - Relevo projetado sobre um papel branco.

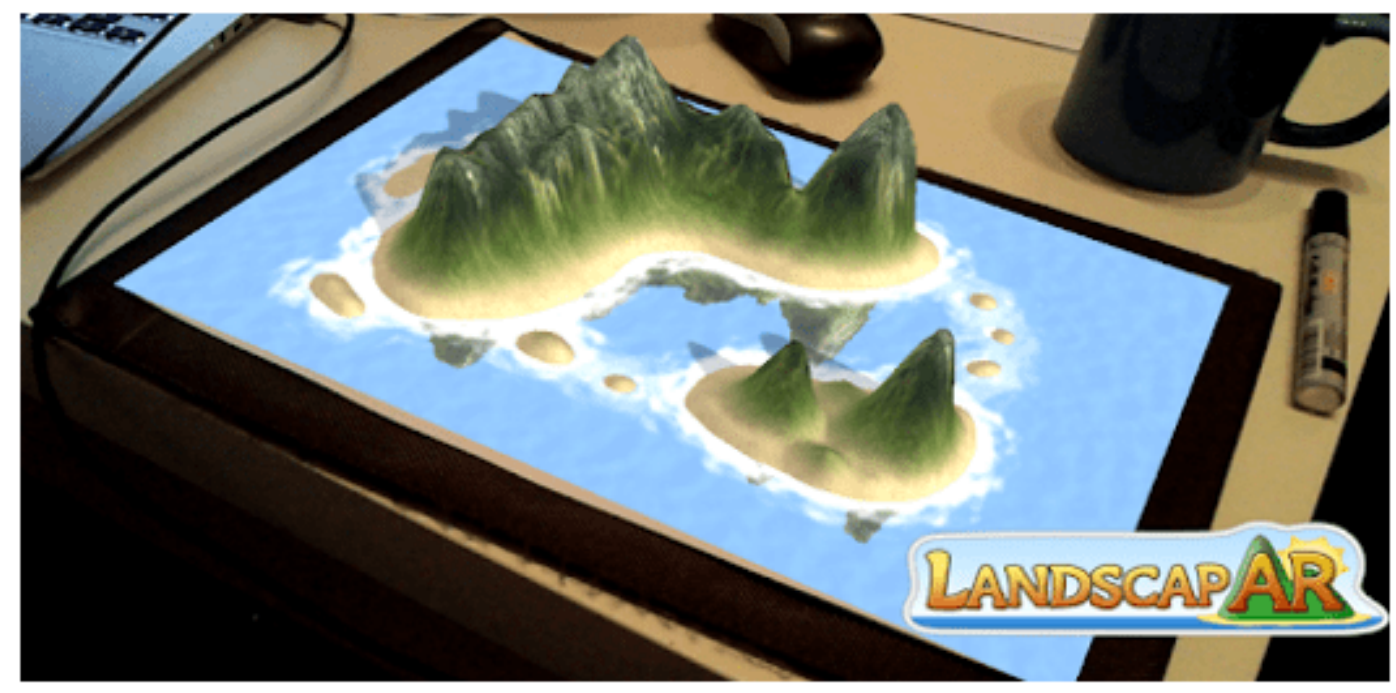

Fonte: https://apps.apple.com/

Desenvolvido por uma empresa sediada na cidade de Berlin - Alemanha, este aplicativo conta com aproximadamente 100 mil downloads na loja de aplicativos da empresa Google. Para projetar uma superfície por meio deste aplicativo basta desenhar as curvas de nível com uma caneta permanente de cor preta em um papel 
branco em cima de uma superfície preta. Após esta etapa, basta abrir o aplicativo e apontar a câmera do celular para o desenho que irá escanear e transformar as curvas de nível em um modelo 3D do relevo.

De acordo com Oliveira e Oliveira (2019) o uso do aplicativo LandscapAR contribuiu para tonar as aulas de Geografia mais criativas e proativas. Este aplicativo permitiu aliar os objetivos pedagógicos dos professores com a disposição dos alunos por utilizar novas tecnologias.

Para Silva (2013) com o advento da internet, as pessoas estão passando mais tempo diante da tela do computador, realizando as mais variadas atividades. Este comportamento contribui para a busca por alternativas de aprendizagem mais eficientes. É importante destacar que a inserção da tecnologia ao ensino é tão antiga quanto o próprio surgimento da escrita. E, para que a escrita fosse possível, foi preciso recorrer a outras tecnologias da época como: tabuas de argila, metal, couro e o papel.

A aprendizagem por meio de aplicativos digitais se constitui como ótimas ferramentas para o desenvolvimento de estratégias de ensino. Além de aplicativos relacionados a realidade aumentada, existem aplicações que visam auxiliar no estudo dos lugares por meio de perguntas. Aplicativos como o Geografia mundial (figura 2.a.b.c) podem servir para auxiliar nos estudos de geografia política, entre outros.

Figura 2.a. Logo do aplicativo na loja de aplicativos do Google e da Apple.

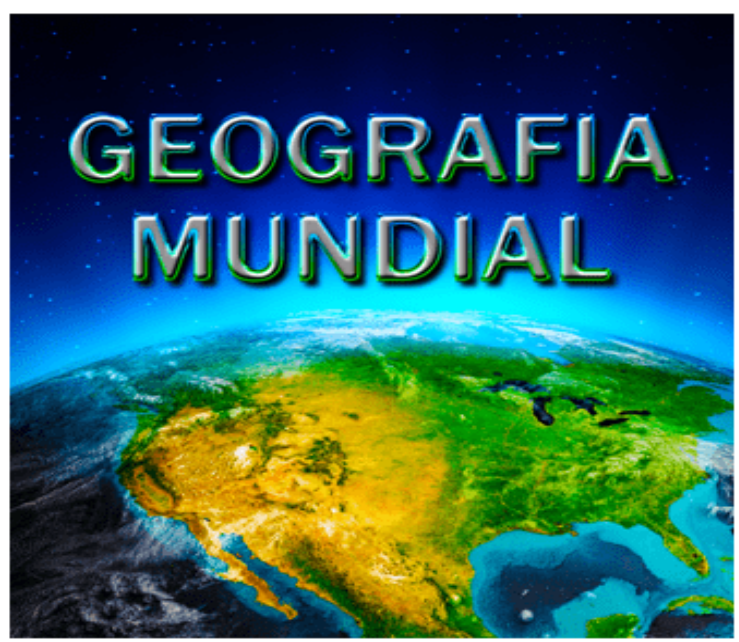


Figura 2.b. Aba onde o aluno pode visualizar um país destacado no mapa e escolher a opinião correspondente.

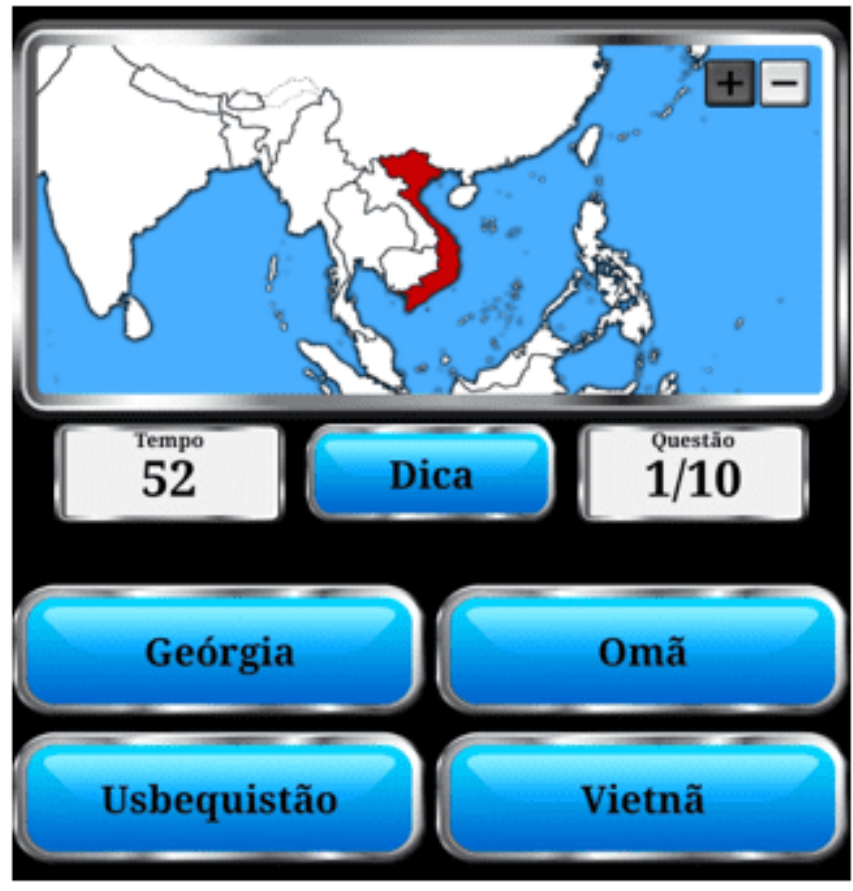

Figura 2.c. Após responder a a pergunta o Jogo apresenta a possibilidade do usuário saber mais acessando o link da Wikipédia.

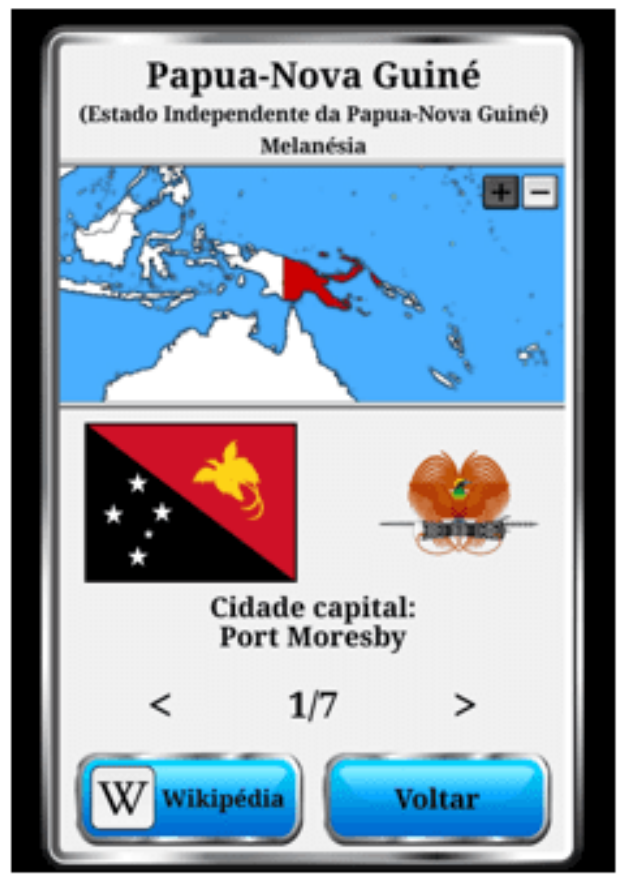

$\mathrm{RC}: 64274$

Disponível em: https://www.nucleodoconhecimento.com.br/geografia/area-de-geografia 
O aplicativo Geografia mundial, disponível para baixar em listas de programas como a playstore da empresa Google, foi desenvolvido pela empresa Atom Games Entretenimento sediada na República Checa. Mesmo não sendo um aplicativo desenvolvido no país, possui tradução para a língua portuguesa. Este aplicativo, que já possui cerca de 10 milhões de downloads, apresenta aspectos da geografia relacionados a cartografia, política e sociedade. Além de possui materiais escritos, possui a possibilidade de integração com sites externos como o Wikipédia.

Mesmo sendo uma importante aplicação, que possibilita o aluno conhecer os aspectos territoriais dos países, trata-se de uma ferramenta que deve ser usada com certa cautela, porque não permite adentrar em conceitos importantes da própria geografia como: aspectos naturais, geopolíticos, entre outros. Por isso, acreditamos este aplicativo deve ser indicado para estudantes do ensino fundamental I que estão começando a estudar as características dos países, pois conhecer a forma territorial destes países é considerado um passo inicial para os demais estudos geográficos.

Amplamente utilizados por estudantes de geografia o aplicativo Onde é isso? (Figura 3), já teve mais de 1 milhão de downloads ao redor do mundo. Este aplicativo foi desenvolvido pela empresa Jaysquared em Hamburgo, Alemanha. Trata-se de uma aplicação que está presente em cerca de 91 países e permitem os estudantes aprenderem sobre as capitais, estados e cidades dos diferentes países.

Figura 3 - Aplicativo Onde é isso?.

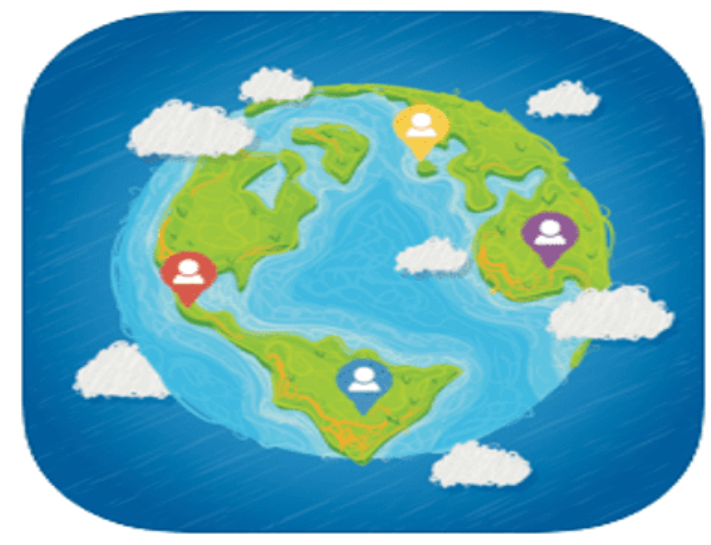

Fonte: https://apps.apple.com/br/app/onde-\%C3\%A9-isso/id492240967 
Atualmente este jogo que disponibiliza mais de 1500 locais que devem ser localizados no mapa pelo usuário. Também é baseado na utilização de dados da Wikipédia para trazer informações sobre cada território representado. Na figura 4.a é possível visualizar a tela principal do aplicativo que permite escolher o tipo de jogo (Mapa ou Quiz). O jogado poderá escolher um mapa plano ou colorida. A figura 4.b representa a tela com o nome do país indicado pelo aplicativo. Nesta etapa o usuário deverá tocar diretamente no mapa na forma correspondente de cada país.

Figura 4a. Tela principal do aplicativo.

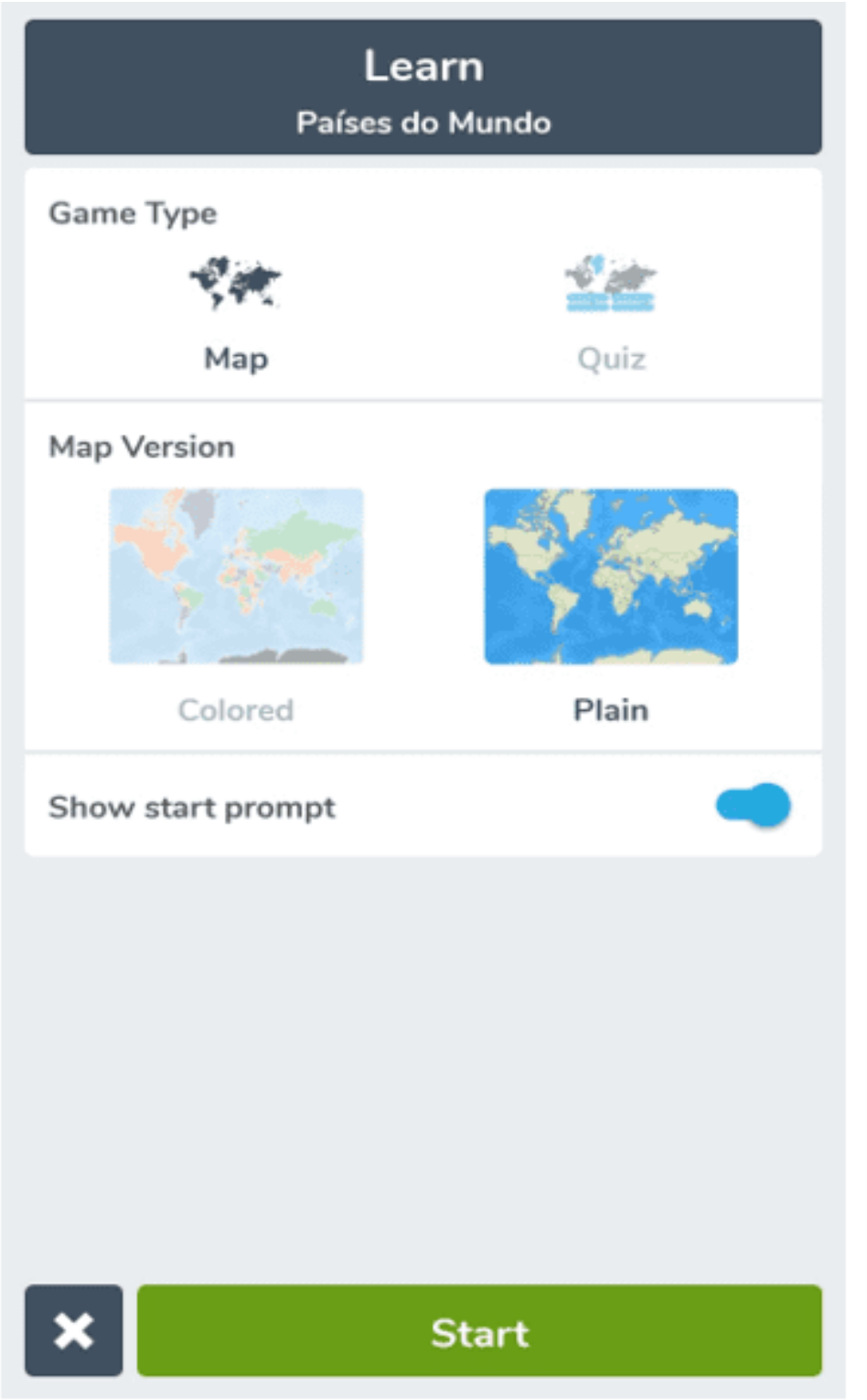


Figura 4.b Tela onde os jogadores respondem as perguntas.

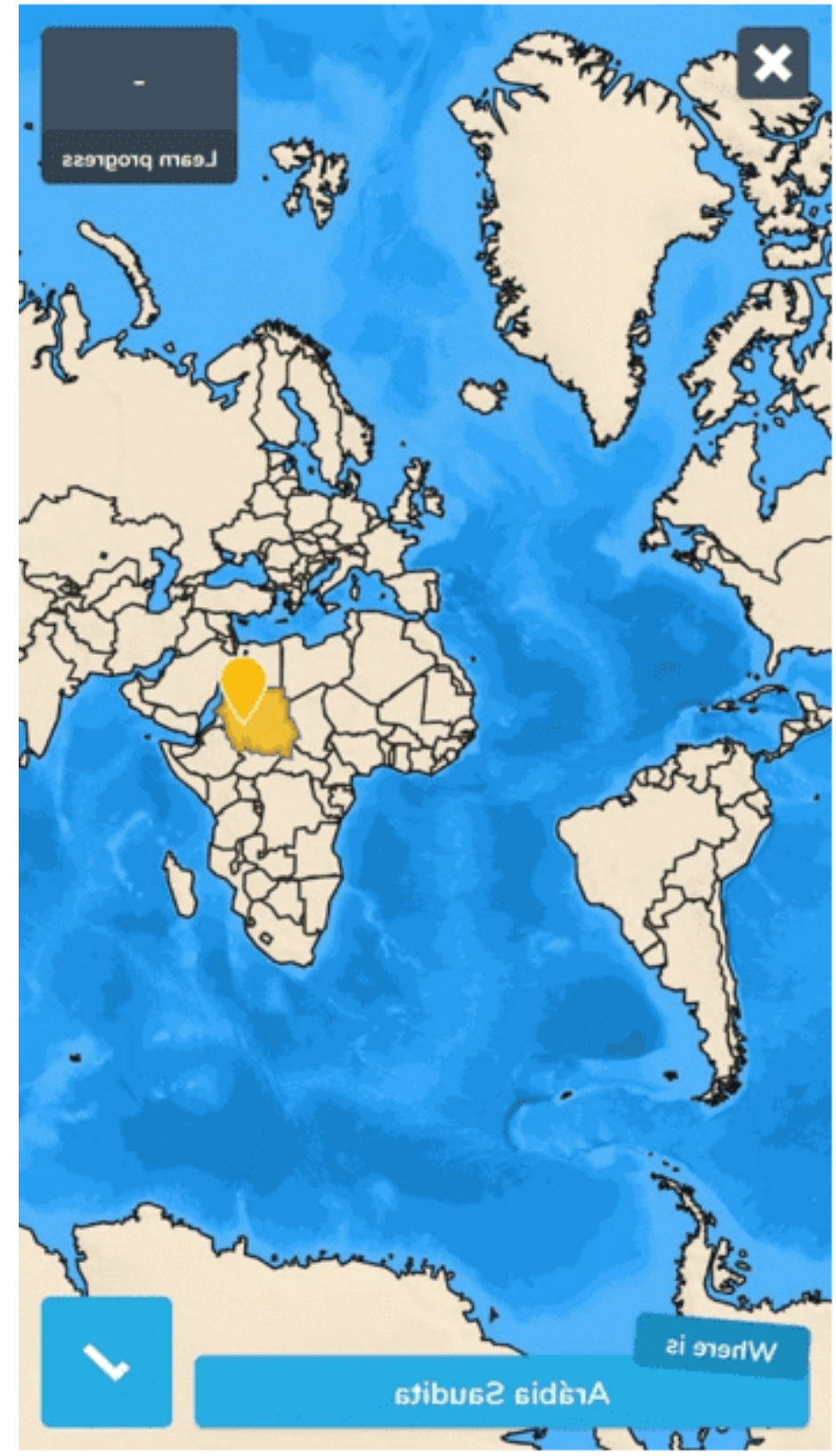

A utilização dos aplicativos descritos logo acima podem ajudar a cumprir uma das metas da BNCC para o ensino de geografia no ensino fundamental, que é de ajudar os alunos a responderem questões relacionadas a sua localização, tais como: onde se localiza? Por que se localiza? Como se distribui? A partir destas perguntas se torna possível trabalhar temas relacionados as características socioespaciais e ambientais dos lugares. Neste sentido, Correa afirma que 
É baseada nesse contexto que a tecnologia deve ser inserida nas escolas, não sendo vista como um fim, acabado, imposto e inalterável, mas como um meio, que visa desvendar, incrementar, analisar e vivenciar a prática do professor em sala de aula, com um único objetivo, 0 de fornecer e despertar o interesse do aluno pelo conhecimento científico (CORREA, 2010 p. 92).

Mesmo com a importância dos aplicativos e plataformas educacionais para o ensino, cabe destacar que o acesso a tecnologia pela população mais carente ainda é limitado. Pinto (2004) destaca que em uma sociedade onde há a desigualdade é tão profunda a escola pública torna-se a única fonte de acesso a internet dos alunos. Isso demonstra a necessidade de políticas educacionais que visem a inclusão tecnológica dos alunos que vivem em condições de pobreza.

\section{CONSIDERAÇÕES FINAIS}

Nos últimos anos a tecnologia tem influenciado cada vez mais a forma como as pessoas se relacionam, trabalham, aprendem e se comunicam com outras pessoas. A área educacional também tem passado por grandes mudanças, onde aplicativos, equipamentos e plataformas de ensino tem ganhado espaço enquanto ferramenta de auxílio ao ensino e aprendizagem.

Independentemente do tipo de inovação presente na educação, esta deve ter como objetivo principal valorizar o ensino, e se posicionar enquanto ferramenta capaz de auxiliar na reprodução do saber para que o público principal, os alunos, possam ter mais oportunidades no âmbito pessoal e profissional.

Neste trabalho foi possível notar que há tecnologias que podem ser grandes aliadas no ensino de geografia, com destaque para as tecnologias baseadas em realidade aumentada, realidade virtual e em multimídias. Os aplicativos citados ao longo do texto podem ser úteis para o ensino de conteúdos geográficos, porém nunca podem ser utilizados como única ferramenta de ensino.

Saber aplicar as ferramentas tecnológicas no contexto educacional do ensino de geografia será primordial para o sucesso e divulgação de conteúdos geográficos, que 
poderão ser uteis para formar uma sociedade mais consciente do seu papel no mundo. Para que isso ocorra, os professores da área deverão estar atentos e preparados para inovar no processo de ensino a partir das diversas ferramentas disponíveis.

Mesmo com o uso de tecnologias por parte dos alunos é possível afirmar que os professores de geografia ainda possuem um papel primordial na inserção curricular por meio das TIC's que contribuem para o ensino de geografia, pois é o professor o verdadeiro responsável pelo correto emprego destas tecnológicas. O sucesso do uso destas tecnologias educacionais também irá depender das competências que os professores da área possuem em mobilizar os alunos para o aprendizado por meio das diferentes ferramentas disponíveis.

Os aplicativos analisados demonstram um potencial para o ensino de geografia, principalmente para alunos do Fundamental I ou que estejam tendo os primeiros contatos com esta ciência. Porém, cabe ressaltar são limitados quanto ao aprofundamento das informações referentes aos países. Destaca-se que estes aplicativos não devem substituir os professores na função de ensinar sobre as características territoriais dos países, mais servirem com complemento.

\section{REFERÊNCIAS}

BAPTISTA, Maria das Graças de Almeida et al. Inovações tecnológicas, educação e necessidades do capital. Revista Ibero-Americana de Estudos em Educação, v. 15, n. $1, \quad$ p. 289-304, 2020. Disponível em: https://periodicos.fclar.unesp.br/iberoamericana/article/view/12710/8813. Acesso em: 11 ago. 2020.

BRITO, Glaucia da Silva; PURIFICAÇÃO, Ivonélia da. Educação e novas tecnologias: um repensar. 2. ed. Curitiba: Ibpex, 2008.

CORREA, Márcio Greyck Guimarães; FERNANDES, Raphael Rodrigues; PAINI, Leonor Dias. Os avanços tecnológicos na educação: o uso das geotecnologias no ensino de geografia, os desafios e a realidade escolar. Acta Scientiarum. Human 
and Social Sciences, v. 32, n. 1, p. 91-96, 2010. Disponível em: https://www.redalyc.org/pdf/3073/307325337011.pdf. Acesso em: 12 ago. 2020.

CUNHA, Maria Isabel. Inovações na educação superior: impactos na prática pedagógica e nos saberes da docência. Em Aberto, v. 29, n. 97, 2016. Disponível em: http://rbep.inep.gov.br/ojs3/index.php/emaberto/article/view/3172/2907. Acesso em: 12 ago. 2020.

FINO, Carlos Nogueira. Investigação e inovação (em educação). Pesquisar para mudar (a educação), p. 29-48, 2011. Disponível em: https://digituma.uma.pt/bitstream/10400.13/813/1/Fino21.pdf. Acesso em: 13 ago. 2020.

GARCIA, Joyce Cordeiro Heindyk; CAMAS, Núria Pons Vilardell. Professor corregente e o uso de tecnologias educacionais. Revista Divers@!, v. 12, n. 2, p. 144-154, 2020. Disponível em: https://revistas.ufpr.br/diver/article/view/69573/40677. Acesso em: 25 set. 2020.

GEBRAN, Maurício Pessoa. Tecnologias educacionais. Curitiba - PR. Ed. IESDE BRASIL SA, 2009. 228 p.

GIORDAN, Marcelo; JACOBSOHN, Liliana Vasconcellos; FILATRO, Andrea. Balanço de Inovações em Educação On-Line. Revista Digital de Tecnologia Educacional e Educação à Distância, v. 2, n. 1, 2005. Disponível em: https://www.pucsp.br/tead/n2/pdf/artigo9.pdf. Acesso em: 14 ago. 2020.

GUERRA, Maria das Graças Gonçalves Vieira; GOMES, Cláudia Suely Ferreira; RIBEIRO, Wagner Leite. Sala de aula digital e o uso das novas tecnologias na educação: perspectivas freireanas. Diálogos Interdisciplinares. Volume 9, Número 5 (2020).

em:

https://revistas.brazcubas.br/index.php/dialogos/article/view/946/920. Acesso em: 15 ago. 2020. 
IZOTON, Clayton Augusto Fontana. A importância do professor tutor na aprendizagem em cursos de educação a distância - EAD. In: SILVA, Gabriel Calefe Pereira da; JORGE, Welington Junior (org.). Tecnologias educacionais: uma abordagem contemporânea. Maringá, PR: Uniedusul, 2020. p. 5 - 17.

JÚNIOR, Airton José Vinholi; MELLO, Dante Alighieri Alves de; GOBARA, Shirley Takeco. Pesquisas em Tecnologias Educacionais em um Programa de Pósgraduação em Educação. Roteiro, v. 45, 2020. Disponível em: https://portalperiodicos.unoesc.edu.br/roteiro/article/view/21476/14257. Acesso em 12 ago. 2020.

KENSKI, Vani Moreira. Educação e Tecnologias: o novo ritmo da informação. 8. ed. Campinas, SP: Papirus, 2012.

MORAN, José. Inovações pedagógicas na educação superior presencial e a distância. Texto adaptado do livro Novas Tecnologias e Mediação Pedagógica, Papirus, v. 2103, 2015. Disponível em: http://www2.eca.usp.br/moran/wpcontent/uploads/2013/12/inovac\%C3\%B5es.pdf. Acesso em: 16 ago.2020.

OLIVEIRA, Eliana; ENS, Romilda Teodora; ANDRADE, Daniela B. S. Freire; MUSSIS, Carlo Ralph de. Análise de conteúdo e pesquisa na área da educação. Revista Diálogo Educacional, Curitiba, v. 4, n.9, p.11-27, maio/ago. 2003. Disponível em: https://periodicos.pucpr.br/index.php/dialogoeducacional/article/view/6479/6383. Acesso em: 06 de ago. 2020.

OLIVEIRA, Isolina; COURELA, Conceição. Mudança e inovação em educação: o compromisso dos professores. Interacções, v. 9, n. 27, 2013. Disponível em: https://revistas.rcaap.pt/interaccoes/article/view/3404. Acesso em: 28 set. 2020.

OLIVEIRA, Érico Anderson de; OLIVEIRA, Rosália Caldas Sanábio de (2019). O uso do aplicativo LandscapAR como recurso pedagógico para o ensino de Geografia. Geosaberes. DOI: 10.26895/geosaberes.v10i22.805 Acesso em: 30 set. 2020. 
PINTO, Álvaro Vieira. O conceito de tecnologia. 2. ed., Rio de Janeiro: Contraponto, 2005.

SILVA, Priscilla Chantal Duarte; SHITSUKA, Ricardo; DE MORAIS, Gustavo Rodrigues. Estratégias de ensino/aprendizagem em ambientes virtuais: estudo comparativo do ensino de língua estrangeira no sistema $\mathrm{EaD}$ e presencial. Revista Brasileira de Aprendizagem Aberta e a Distância, v. 12, 2013. Disponível em: < http://seer.abed.net.br/index.php/RBAAD/article/view/243/121>. Acesso em: 9 ago. 2020.

SOUSA, Galdino Rodrigues de; BORGES, Eliane Medeiros; COLPAS, Ricardo Ducatti. EM DEFESA DAS TECNOLOGIAS DE INFORMAÇÃO E COMUNICAÇÃO NA EDUCAÇÃO BÁSICA: diálogos em tempos de pandemia. PLURAIS-Revista Multidisciplinar, v. 5, n. 1, p. 146-169, 2020. Disponível em: http://www.revistas.uneb.br/index.php/plurais/article/view/8883/5690. Acesso em: 04 ago. 2020.

SOUZA, Kênia Paulino de Queiroz; PINHO, Maria José de. Criatividade e inovação na escola do século XXI: uma mudança de paradigmas. Revista Ibero-Americana de Estudos Em Educação, v. 11, n. 4, p. 1906-1923, 2016. Disponível em: https://dialnet.unirioja.es/servlet/articulo?codigo=6202946. Acesso em: 06 ago.2020.

\section{APÊNDECE - REFERÊNCIAS DE NOTA DE RODAPÉ}

3. Cabe ressaltar que o avanço da internet e das tecnologias associadas a ela só teve grande expansão graças aos investimentos públicos. Esta intervenção contribuiu para diminuir o enorme atraso que o país tinha em relação a estas tecnologias. Atualmente, embora o Estado ainda tenha um importante papel nesta área, são as grandes multinacionais e empresas de telecomunicações que concentram o monopólio da internet no país.

4. Oliveira e Courela (2013 p.105) destacam que as inovações no campo educacional geralmente envolvem o atendimento de questões locais e que raramente envolvem a 
escola em todo o seu conjunto. Para que haja mudanças maiores, seria necessária uma reforma. Aqui o conceito de reforma se refere a uma mudança que ocorre em um nível mais amplo.

Enviado: Outubro, 2020.

Aprovado: Novembro, 2020. 